\title{
EDITORIAL
}

\section{TRABAJO DECENTE PARA ENFERMERÍA SUSTENTADO EN EVIDENCIAS}

\author{
DECENT WORK FOR EVIDENCE-BASED NURSING
}

Dra. María Olga Quintana Zavala

Jefa del Departamento de Enfermería. Universidad de Sonora, México

\begin{abstract}
El trabajo decente es el que se realiza con respeto a los principios y derechos laborales fundamentales, permite un ingreso justo y proporcional al esfuerzo realizado, sin discriminación de género o de cualquier otro tipo, garantiza el cumplimiento de los derechos de los trabajadores, oportunidades de empleo, protección y diálogo social (1). Los indicadores del trabajo decente que afectan a las aptitudes y al bienestar de los trabajadores se relacionan con características de la situación laboral, como el uso de las competencias profesionales, el horario del trabajo, el desplazamiento al lugar de trabajo, la seguridad y salud de los trabajadores y las condiciones generales del trabajo (2).
\end{abstract}

Bajo esta perspectiva surge la siguiente interrogante: ¿El trabajo de enfermería es realmente un trabajo decente? Pregunta con grandes implicancias, debido a que la situación de la enfermería es heterogénea según el país, la región, incluso la ciudad y/o institución donde se ejerce la profesión, relacionado a los efectos de la globalización y la economía imperante, que determina, de forma positiva o negativa, muchas de las condiciones laborales de la población en general, lo que alcanza a los profesionales de enfermería.

En este sentido, las oportunidades de empleo y sueldo digno difieren según el nivel de desarrollo económico del país; por ejemplo, en los Estados Unidos de América el Departamento del Trabajo proyecta que las oportunidades de empleo para enfermeras y enfermeros profesionales aumentarán en un 19\% entre los años 2012 y 2022 (oportunidades más altas que en todas las ocupaciones), lo que se atribuye al incremento en la demanda de cuidado profesional relacionado al envejecimiento poblacional, el incremento de las enfermedades crónicas, a un mayor número de personas con acceso a los servicios de salud, a la creciente necesidad de cuidados a largo plazo y a domicilio, a la necesidad de abrir más centros de rehabilitación y atención ambulatoria, así como de reemplazar al personal de enfermería que se jubila, entre otras (3). 
Mientras que en países latinoamericanos las enfermeras y enfermeros profesionales se emplean casi inmediatamente cuando concluyen su formación, lamentablemente algunos son contratados en condiciones de trabajo inestables, ya que son empleos eventuales, lo que favorece la disminución de la satisfacción laboral y en algunos casos genera la intención de migrar, hecho que no es privativo para el profesional de enfermería. A nivel mundial se estima que hay 232 millones de migrantes internacionales, lo cual representa el 31,1\% de la población mundial, sin embargo, el 48\% de los migrantes internacionales son mujeres, quienes lo hacen por motivos laborales (4). En el caso de las enfermeras, no es fácil que logren insertarse de forma legal en el mercado laboral de un país con mayor crecimiento económico; aunque existen agencias de empleo dedicadas a gestionar la contratación de enfermeras en el extranjero, el costo económico de dichos servicios es alto y debe ser financiado por las mismas enfermeras.

Aun con eso, el panorama general en países latinoamericanos en cuanto a las oportunidades de empleo para enfermeras y enfermeros es alentador, al compararlo con otras profesiones, sin embargo, es necesario tomar en cuenta dos aspectos importantes: las condiciones de empleo y los sistemas de pensiones o jubilación. En cuanto a las condiciones de empleo de las enfermeras y enfermeros, está documentado que el equipo de enfermería enfrenta condiciones laborales inadecuadas en su medio ambiente de trabajo, que pueden dar lugar a alteraciones en su salud física y mental, relacionada a la organización del trabajo (jornada excesiva, déficit profesional, estrecha supervisión), factores del medio ambiente (mobiliario y equipos inadecuados y obsoletos) y sobrecargas en los segmentos corporales. Ello puede producir incremento de estrés, violencia laboral, entre otras situaciones negativas, además de lesiones musculo-esqueléticas que están asociadas a la insuficiencia de las condiciones ambientales de trabajo (5), como permanecer de pie períodos prolongados (6), en posturas inadecuadas (7), lo que genera mayor absentismo, solicitud de permisos y retiro por discapacidad en enfermeras y enfermeros (8).

En cuanto a los sistemas de pensiones o jubilación para enfermeras, requieren de especial análisis, incluso en países desarrollados, debido a que la reducción de los beneficios de jubilación amenaza cada vez más a los trabajadores, lo que en el caso de los profesionales de enfermería adhiere un grado de vulnerabilidad, por el hecho de ser una profesión eminentemente femenina, por lo que el salario promedio es más bajo, lo que representa un riesgo de pobreza en la vejez, ya que el trabajo en turnos, durante vacaciones, días festivos y períodos de guardia incrementa de 10 a 20\% la remuneración de enfermeras, lo que no se toma en cuenta en el cálculo de las pensiones o jubilación y representa una base salarial baja, sobre la cual se estima el pago de las jubilaciones (9).

Es en este sentido que la labor de los Colegios y Asociaciones de Enfermería debe enfocarse también, entre otros aspectos, en promover a nivel de políticas públicas 
cambios estructurales que propicien el trabajo decente para enfermeras y enfermeros. Los gobiernos y las instituciones de salud deben de reconocer que el trabajo de enfermería es sumamente valioso para la salud de las poblaciones, por lo que es necesario desarrollar estrategias que propicien mejores ambientes laborales, que promuevan, además, la disminución de riesgos y que motiven a ingresar y permanecer en el ejercicio de la profesión (10), sin presiones de cualquier naturaleza, en un entorno que garantice la seguridad e integridad personal y profesional, con los recursos necesarios que le permitan el óptimo desempeño de sus funciones, recibir trato digno, tener acceso a diferentes alternativas de desarrollo profesional, asociarse libremente para impulsar, fortalecer y salvaguardar sus intereses profesionales, y acceder a posiciones de toma de decisión de acuerdo a sus competencias, sin discriminación alguna, en igualdad de condiciones con otros trabajadores (11).

\section{REFERENCIAS}

1. Organización Internacional del Trabajo. Situación del Trabajo Decente en México [Internet]. México D.F.: Oficina de Países de la OIT para México y Cuba; 2013 [citado 8 julio 2015]. 8 p. Disponible en: http://www.ilo.org/ wcmsp5/groups/public/@americas/@ro-lima/@ilo-mexico/documents/ genericdocument/wcms_230532.pdf

2. Tostes M. Manual de uso e interpretación de las estadísticas laborales [Internet]. Lima: OIT/Oficina de la OIT para los Países Andinos; 2012 [citado 8 julio 2015]. 334 p. Disponible en: http://www.ilo.org/wcmsp5/groups/public/---americas/--ro-lima/documents/publication/wcms_216075.pdf

3. Oficina de Estadísticas Laborales, Departamento de Trabajo de EE.UU. Occupational Outlook Handbook en Español (OOH), Enfermeros Graduados [Internet]. Washington, D.C.: Oficina de Estadísticas Laborales, Departamento de Trabajo de EE.UU.; 2014-15 [citado 7 julio 2015]. Disponible en: http://www. bls.gov/es/ooh/healthcare/registered-nurses.htm

4. Organización Internacional del Trabajo. Migración laboral: Datos y cifras [Internet]. Ginebra: Organización Internacional del Trabajo; 2014 [citado 10 julio 2015]. Disponible en: http://www.ilo.org/global/about-the-ilo/media-centre/ issue-briefs/WCMS_248866/lang--es/index.htm

5. Montoya Díaz M, MHP Marziale, MLCC Robazzi, FCT Freitas. Lesiones osteomusculares en trabajadores de un hospital mexicano y la ocurrencia del ausentismo. Cienc. enferm. 2010; XVI(2): 35-46. 
6. Hughes NL, Nelson A, Matz MW, Lloyd J. AORN Ergonomic Tool 4: Solutions for Prolonged Standing in Perioperative Settings. AORN J. 2011; 93(6): 767-74.

7. Sikiru L, Shmaila H. Prevalence and risk factors of low back pain among nurses in Africa: Nigerian and Ethiopian specialized hospitals survey study. East Afr J Public Health. 2009; 6(1): 22-5.

8. De Souza CS, Lima da Silva JL, Antunes Cortez E, Schumacher KP, Moreira RCS, De Almeida Nilson T. Riesgos ergonómicos por esfuerzo repetitivo del personal de enfermería en el hospital. Enferm. glob. 2011; 23; 251-6.

9. Fultz E. Decent pensions for nurses - By Hedva Sarfati. Int Soc Secur Rev. 2012. 65(1): 117-120.

10. Quintana Zavala M, Valenzuela Suazo S, Paravic Klijn T. Enfermería desde la perspectiva del Trabajo Decente. Enferm. glob. 2014; 13(33): 302-9.

11. Secretaría de Salud. Comisión Nacional de Arbitraje Médico. Carta de los derechos generales de las Enfermeras y Enfermeros. México DF; 2005. 